\title{
Assessing the blood concentration of new adipocytokines in patients with ischaemic stroke
}

\author{
Aleksandra Kazimierczak-Kabzińska' , Bogdan Marek², Halina Borgiel-Marek³, Dariusz Kajdaniuk2, \\ Beata Kos-Kudła ${ }^{2}$
}

${ }^{1}$ Department of Neurology with Stroke Ward, Provincial Specialist Hospital, Betchatów, Poland

${ }^{2}$ Department of Pathophysiology and Endocrinology, School of Medicine with the Division of Dentistry in Zabrze,

Medical University of Silesia, Katowice, Zabrze, Poland

${ }^{3}$ Department of Craniomaxillofacial and Oral Surgery, Medical University of Silesia in Katowice, Katowice, Poland

\begin{abstract}
Introduction: Ischaemic stroke (IS) is a disease that is a common cause of death and one of the most common causes of disability in adults. There is a continuous need to conduct stroke pathogenesis studies. A certain role here can be attributed to adipose-derived hormones. The aim of this paper is to assess the blood concentration for selected adipocytokines: omentin-1, irisin, protein-1 related with C1q/TNF (CTRP1), vaspin and nesfatin-1 in IS patients, and an attempt to define their role as risk factors for ischaemic stroke.

Material and methods: The study included 46 patients with ischaemic stroke (27 females, 19 males, average 67.6 years of age). The control group consisted of 32 patients ( 16 females, 16 males, average 64.1 years of age) who had never had cerebrovascular diseases.

Results: The concentration of omentin-1 and CTRP1 in the group of stroke patients was higher than in the control group, whereas the concentrations of nesfatin- 1 and irisin was significantly lower than in the control group. The vaspin level was similar in both groups of patients. Statistical analysis using logistic regression allows us to find that CTRP1 can be a significant stroke risk factor. A statistically significant positive correlation was found between the concentration of CTRP1 and NIHSS. However, no correlation between the concentration of other adipocytokines under investigation and the severity of ischaemic stroke was found.

Conclusions: From among the adipocytokines under investigation, higher concentrations of omentin-1 and CTRP1 and lower blood concentrations of nesfatin-1, irisin significantly increase the odds of getting to the group of ischaemic patients. It seems that CTRP1 can be an independent predictive factor of IS. (Endokrynol Pol 2020; 71 (6): 504-511)
\end{abstract}

Key words: ischaemic stroke; adipocytokines; omentin-1; nesfatin-1; CTRP1; irisin; vaspin

\section{Introduction}

Ischaemic strokes (IS) make up about $80 \%$ of all strokes. An insufficient blood flow through cerebral vessels results in cerebral hypoxia, impaired glucose supply, and impaired removal of unnecessary metabolites, which results in a cerebral infarction. Despite the progress in diagnostic and therapeutic methods, IS remains one of the most common causes of long-term disability in adults, being also a significant cause of death. It turns out that both primary and secondary prevention are still very important in health care covering patients with cerebrovascular diseases. Hence, it is extremely important to gain detailed knowledge of the pathology and pathogenesis of stroke [1].

In recent years it has been proven that adipose tissue not only plays the role of basic energy storage and provides body thermal insulation, but it is also an endocrine organ producing many mediators - so-called adipocytokines. It seems that adipose tissue plays a role in regulating many life processes, including appetite, and maintaining metabolic homeostasis. It is the site where steroid and thyroid hormones are metabolised. White adipose tissue participates in many hormonal and inflammatory processes. It affects metabolism by playing a role in shaping energy homeostasis, resistance to insulin, and adipocyte differentiation. The visceral adipose tissue is responsible for local and generalised inflammations and insulin resistance, which is provided by generating and secreting numerous proteins and cytokines, including adiponectin, resistin, leptin, omentin or tumour necrosis factor alpha (TNF- $\alpha$ ), interleukin 6 (IL-6), and monocyte chemoattractant protein-1 (MCP-1) [2, 3].

Studies on the influence of adipose tissue on the atherosclerosis, especially in terms of inflammatory mechanisms, have been conducted for years. The role of adipocytokines in developing diseases, including diabetes, hypertension, thyroid disorders, peripheral vascular diseases, or Alzheimer disease is investigated. 
Obesity, because of its coincidence with developing cardiovascular diseases, is perceived as an increasingly significant clinical problem. The role of adipose tissue and the mechanisms of action of proteins secreted by adipose tissue in the context of IS have not been fully explored [4-6].

Omentin-1 is a protein produced mainly by the visceral adipose tissue, which probably increases the susceptibility of adipose tissue to insulin. It also shows some anti-inflammatory action by reducing the expression of C-reactive protein, tumour necrosis factor, and nuclear transcription factor. It is believed that a reduced omentin level can develop an insulin resistance. Currently, it is known that in patients with type 2 diabetes and in obese people, the omentin level is decreased $[7,8]$.

Irisin is an adipomyokine that is released both in skeletal muscles and in white adipose tissue. Study results show a correlation between the irisin concentration and disorders of carbohydrate metabolism. It seems that it exerts a beneficial influence by maintaining correct carbohydrate metabolism parameters, and it helps improve the insulin sensitivity of tissues. It is also referred to as an antidiabetic hormone [9].

Vaspin sensitises peripheral tissues to insulin and shows a hypoglicemising effect [10, 7]. It can protect the vascular endothelial cells against apoptosis induced by free fatty acids, which suggests its beneficial antiatherosclerotic effect [11].

Nesfatin-1 is an appetite-suppressing neuropeptide generated in the mammalian hypothalamus. Like other appetite stimulating (e.g. ghrelin) or appetite suppressing hormones (e.g. leptin), it also shows some gastroprotective properties - it protects gastric mucosa against damage induced by corrosive factors and stress-induced microbleeds [12, 13].

Tumour necrosis factor- $\alpha$-related protein 1 (CTRP1) is a new adipokine that belongs to the CRTP family and occurs in many tissues. It acts as a key regulator for the metabolism of glucose and lipids. Currently there are 16 members of the CRTP family identified, and they share a common structure [14].

\section{Material and methods}

The study group included 46 patients with IS (27 females, 19 males, average 67.6 years of age). The trial inclusion criterion is confirmed IS defined as a clinical syndrome featuring a sudden focal, sometimes generalised brain function disorder with symptoms persisting longer than 24 hours. Blood for tests was collected within 24 hours of detecting the first symptoms and before implementing treatment. Trial exclusion criteria include the following: haemorrhagic stroke, subarachnoid haemorrhage, brain tumour or any type of cancer, kidney/liver failure, severe infection, injury, surgery, myocardial infarction (MI) diagnosed over the last month, as well as diabetes in history.
The control group included 32 patients ( 16 females, 16 males, average 64.1 years of age) without cerebrovascular diseases in history, who had not suffered any chronic diseases except for back pain syndrome and arterial hypertension.

The patients underwent routine laboratory tests [complete blood count $(\mathrm{CBC})$, total cholesterol, low-density lipoprotein (LDL), high-density lipoprotein (HDL), triglycerides (TG), electrolyte level: sodium $(\mathrm{Na})$, potassium $(\mathrm{K})$, magnesium $(\mathrm{Mg})$, chloride $(\mathrm{Cl})$, thyroid-stimulating hormone (TSH), free triiodothyronine (fT3), free thyroxine (fT4), C-reactive protein (CRP), creatinine, fasting glycaemia, and international normalised ratio (INR)]. Their body mass index (BMI) was also calculated. Ischaemic stroke patients were subject to stroke severity evaluation by using the Barthel scale on day 1 and 9 after stroke and the National Institutes of Health Stroke Scale (NIHSS scale), and they underwent blood flow tests in extra and intracranial arteries by using Doppler ultrasound method to assess the occurrence of stenosis and to assess the intima media thickness (IMT).

An additional full blood sample $(20 \mathrm{~mL})$ was collected from each patient. The blood was centrifuged, and the serum obtained was frozen at $-80^{\circ} \mathrm{C}$. Once all the materials were ready, the levels of omentin-1, irisin, CTRP1, vaspin were determined by using commercially available immunoenzymatic test kits from BioVendor, while the concentration of nesfatin- 1 was measured by using a test kit manufactured by Cloud-Clone Crop.

The database was created in Microsoft EXCEL v. 2010, and statistical calculations were conducted by using licensed statistical packages: Statistica v. 7.1 PL supplied by StatSoft, MedCalc Statistical Software v.14.10.2 and PQStat Software v. 1.6.6. During the statistical analysis a significance level of $p<0.05$ was assumed. The distribution of variables was determined by using the Shapiro-Wilk test. In addition, the following statistical tests were used: parametric Student's t-test, Fisher's exact test for two variances, Mann-Whitney U test, chi-square test of independence, Pearson's correlation coefficient test, nonparametric Spearman's rank correlation coefficient test, and simple and multifactorial logistic regression.

In the past we published a paper that covered different cytokine sets. In the previous study we tested the levels of resistin, chemerin, and visfatin. The same patient base was used for the studies. That is why the study group and control group are identical for both studies. Because the same population of patients was investigated, some of the data can be the same, e.g. general characteristics of the study and control group, presented in Table 1 [15].

The Bioethics Committee operating at the Regional Medical Chamber in Łódź (K.B. No. -7/17 of 5 April 2017) granted permission to conduct the study.

\section{Results}

No statistically significant differences were noticed between the study and control group in terms of basic biochemical parameters and BMI, while with the group with IS the percentage of patients with elevated fasting glycaemia and elevated CRP as well as with lower potassium concentration was higher (Tab. 1).

The concentration of omentin- 1 in the study group ranged from 196 to $1159.7 \mathrm{ng} / \mathrm{mL}$, with an average value of $487.1 \pm 201.22 \mathrm{ng} / \mathrm{mL}$, while in the control group it ranged from 183.2 to $561.1 \mathrm{ng} / \mathrm{mL}$, with an average value of $362.4 \pm 106.29 \mathrm{ng} / \mathrm{mL}$. In the study group the concentration of omentin- 1 was statistically significantly higher than in the control group $(p=0.0084)$ (Tab. 2).

The concentration of irisin in the study group ranged from 3.09 to $8.69 \mathrm{ng} / \mathrm{mL}$, with an average value 
Table 1. Characteristics of patients with ischaemic stroke (IS) and control group

\begin{tabular}{|c|c|c|c|}
\hline & Ischaemic stroke $(n=46)$ & Control (n = 32) & $p$ value \\
\hline Age (years) & $67.6(S D \pm 12.92)$ & $64.1(S D \pm 64.1)$ & 0.0851 \\
\hline Total cholesterol [mg/dL] & $186(S D \pm 55.52)$ & $195.6(S D \pm 35.77)$ & 0.2161 \\
\hline $\mathrm{HDL}[\mathrm{mg} / \mathrm{dL}]$ & $50.7(S D \pm 14.12)$ & $57.8(S D \pm 11.28)$ & 0.0093 \\
\hline LDL [mg/dL] & $118.7(S D \pm 39.4)$ & $130.6(\mathrm{SD} \pm 34.48)$ & 0.1892 \\
\hline $\mathrm{TG}[\mathrm{mg} / \mathrm{dL}]$ & $148.1(\mathrm{SD} \pm 78.81)$ & $118.7(S D \pm 63.51)$ & 0.1042 \\
\hline $\mathrm{Na}[\mathrm{mmol} / \mathrm{L}]$ & $139.3(S D \pm 3.13)$ & $139.6(S D \pm 2.55)$ & 0.6772 \\
\hline $\mathrm{K}[\mathrm{mmol} / \mathrm{L}]$ & 3.93 (SD \pm 0.45$)$ & $4.22(S D \pm 0.47)$ & 0.0078 \\
\hline $\mathrm{Mg}[\mathrm{mg} / \mathrm{dL}]$ & $1.98(S D \pm 0.25)$ & $2.02(S D \pm 0.2)$ & 0.1793 \\
\hline $\mathrm{Cl}[\mathrm{mmol} / \mathrm{L}]$ & $102.7(S D \pm 4.25)$ & $103(S D \pm 3.2=19)$ & 0.5681 \\
\hline Creatine [mg/dL] & $0.88(S D \pm 0.28)$ & 0.76 (SD \pm 0.19$)$ & 0.5681 \\
\hline TSH [ulU/mL] & $1.72(S D \pm 1.69)$ & $1.29(S D \pm 0.94)$ & 0.4951 \\
\hline fT3 [pg/dL] & $2.68(S D \pm 0.59)$ & $2.71(S D \pm 0.54)$ & 0.7862 \\
\hline $\mathrm{fT} 4$ [ng/dL] & $1.45(S D \pm 0.4)$ & $1.29(S D \pm 0.21)$ & 0.1425 \\
\hline Thrombocytes [K/uL] & $231(S D \pm 73)$ & $234.5(S D \pm 52.3)$ & 0.4887 \\
\hline Leukocytes [K/uL] & $8.63(S D \pm 2.43)$ & $8.05(S D \pm 2.55)$ & 0.2223 \\
\hline CRP $[\mathrm{mg} / \mathrm{dL}]$ & $0.57(S D \pm 0.73)$ & 0.33 (SD \pm 0.53$)$ & 0.0367 \\
\hline Fasting glycaemia [mg/dL] & $107.7(S D \pm 32.4)$ & $93.8(S D \pm 10.7)$ & 0.0477 \\
\hline BMI & $27.3(S D \pm 4.5)$ & $27.4(S D \pm 4.1)$ & 0.9615 \\
\hline
\end{tabular}

HDL — high-density lipoprotein; LDL — low-density lipoprotein; TG — triglycerides; $\mathrm{Na}$ — sodium; $\mathrm{K}$ — potassium; $\mathrm{Mg}$ — magnesium; $\mathrm{Cl}$ — chlorine; TSH — thyroid stimulating hormone; fT3 — triiodothyronine; fT4 — thyroxine; CRP — C-reactive protein; BMI — body mass index

Table 2. Omentin-1, vaspin, irisin, nesfatin-1, and CTRP1 in patients with ischaemic stroke (IS) and in the control group

\begin{tabular}{lccc}
\hline & Ischaemic stroke $(\mathbf{n}=\mathbf{4 6})$ & Control $(\mathbf{n}=\mathbf{3 2})$ & $\mathbf{p}$ value \\
\hline Omentin-1 $[\mathrm{ng} / \mathrm{mL}]$ & 487.1 & 362.4 & $\mathbf{p}=\mathbf{0 . 0 0 8 4}$ \\
\hline Irisin $[\mathrm{ng} / \mathrm{mL}]$ & 4.86 & 6.13 & $\mathbf{p}<\mathbf{0 . 0 0 0 1}$ \\
\hline Vaspin $[\mathrm{ng} / \mathrm{mL}]$ & 0.217 & 0.23 & $\mathrm{p}=0.5646$ \\
\hline Nesfatin-1 $[\mathrm{ng} / \mathrm{mL}]$ & 295.8 & 387.5 & $\mathbf{p}=\mathbf{0 . 0 2 8 2}$ \\
\hline CTRP1 $[\mathrm{ng} / \mathrm{mL}]$ & 447.8 & 335.4 & $\mathrm{p}=0.0002$ \\
\hline
\end{tabular}

CTRP1 — protein-1 related with C1q/TNF

of $4.86 \pm 1.31 \mathrm{ng} / \mathrm{mL}$, while in the control group it ranged from 1.57 to $9.1 \mathrm{ng} / \mathrm{mL}$ with an average value of $\pm 6.07 \mathrm{ng} / \mathrm{mL}$. In the group of IS patients the concentration of irisin was statistically significantly lower than in the control group ( $p<0.0001$ ) (Tab. 2).

The concentration of vaspin in the study group ranged from 0.031 to $0.655 \mathrm{ng} / \mathrm{mL}$, with an average value of $0.217 \pm 0.161 \mathrm{ng} / \mathrm{mL}$, while in the control group it ranged from 0.057 to $0.688 \mathrm{ng} / \mathrm{mL}$, with an average value of $0.23 \pm 0.874 \mathrm{ng} / \mathrm{mL}$. A comparison of the concentration of vaspin in both groups did not reveal any statistically significant differences $(\mathrm{p}<=0.5646)$ (Tab. 2).

The concentration of nesfatin- 1 in the study group ranged from 58 to $850.6 \mathrm{ng} / \mathrm{mL}$, with an average value of $295.8 \pm 175.7 \mathrm{ng} / \mathrm{mL}$, while in the control group it ranged from 126.9 to $864.5 \mathrm{ng} / \mathrm{mL}$, with an average value of $387.5 \pm 0.874 \mathrm{ng} / \mathrm{mL}$. In the study group the concentration of nesfatin- 1 was significantly lower than in the control group ( $\mathrm{p}=0.0282)$ (Tab. 2).

The level of CTRP1 in the study group ranged from 200 to $949.5 \mathrm{ng} / \mathrm{mL}$, with an average value of $447.8 \pm 1.31 \mathrm{ng} / \mathrm{mL}$, while in the control group it ranged from 205 to $689, \mathrm{ng} / \mathrm{mL}$, with an average value of $335.4 \pm 104.1$. In the group of IS patients the concentration of that adipocytokine was statistically significantly higher than in the control group $(\mathrm{p}<0.0002)$ (Tab. 2).

Logistic regression allowed us to assess that CTRP 1 was a significant risk factor for stroke (Tab. 3).

A statistically significant correlation between the concentration of omentin-1, CTRP1, nesfatin-1, and the age of patients in the study group was found. The concentration of omentin-1 and CRTP1 increased 
Table 3. Multifactorial logistic regression for CTRP1

\begin{tabular}{|c|c|c|c|c|c|}
\hline \multicolumn{6}{|c|}{ Multifactorial logistic regression $\left(p<0.0001 ; R_{\text {Nagelkere }}^{2}=0.2937\right)$} \\
\hline & Coefficient & St. error & $\mathbf{p}$ & Odds ratio & $95 \% \mathrm{Cl}$ \\
\hline CTRP1 & 0.0078 & 0.0023 & 0.0201 & 1.0078 & $1.0012-1.0145$ \\
\hline Fixed & -5.8865 & 4.0670 & 0.1478 & & \\
\hline
\end{tabular}

CTRP1 — protein-1 related with C1q/TNF; $\mathrm{Cl}$ — confidence interval

Table 4. The correlation between omentin-1, vaspin, irisin nesfatin-1, CTRP1, and the age of ischaemic stroke patients

\begin{tabular}{lcc}
\hline & $\mathbf{R}$ & $\mathbf{p}$ value \\
\hline Omentin-1 and age & 0.3865 & $\mathbf{0 . 0 2 1 8}$ \\
\hline Irisin and age & 0.1518 & 0.3138 \\
\hline Vaspin and age & -0.0601 & 0.6914 \\
\hline Nesfatin-1 and age & -0.3039 & $\mathbf{0 . 0 4 2 4}$ \\
\hline CTRP1 and age & 0.5173 & $\mathbf{0 . 0 0 0 2}$ \\
\hline
\end{tabular}

CTRP1 — protein-1 related with C1q/TNF

with the age of patients in the study group, while the concentration of nesfatin-1 decreased. This correlation was not observed for the remaining adipocytokines (Tab. 4).
No differences in adipocytokine blood concentrations between male and females were found (Tab. 5).

A statistically significant positive correlation was found between the concentration of CTRP1 and the NIHSS. However, such a correlation was not observed for vaspin, omentin-1, nesfatin-1, and irisin. No correlation between the concentrations of the adipocytokines under analysis and the Barthel scale score on day 1 and day 9 in IS patients was found (Tab. 6).

No correlation between the concentrations of adipocytokines under analysis and the IMT was found (Tab. 7).

For the concentrations of omentin-1, irisin, vaspin, and CTRP1 no differences between patients with and without the stenosis of carotid arteries were found. We noted a higher concentration of nesfatin-1 only in patients with stenosis (Tab. 8).

Table 5. Evaluation of average concentrations for omentin-1, vaspin, irisin, nesfatin-1, and CTRP1 in females and males with ischaemic stroke

\begin{tabular}{lccc}
\hline & Females $(\mathbf{n}=\mathbf{2 7})$ & Males $(\mathbf{n}=\mathbf{1 9})$ & $\mathbf{p}$ value \\
\hline Omentin-1 $[\mathrm{ng} / \mathrm{mL}]$ & 516.6 & 452.1 & $\mathrm{p}=0.6121$ \\
\hline Irisin $[\mathrm{ng} / \mathrm{mL}]$ & 4.97 & 4.7 & $\mathrm{p}=0.9648$ \\
\hline Vaspin $[\mathrm{ng} / \mathrm{mL}]$ & 0.244 & 0.180 & $\mathrm{p}=0.2976$ \\
\hline Nesfatin-1 $[\mathrm{ng} / \mathrm{mL}]$ & 280.2 & 319.3 & $\mathrm{p}=0.3639$ \\
\hline CTRP1 $[\mathrm{ng} / \mathrm{mL}]$ & 484.4 & 395.7 & $\mathrm{p}=0.0818$ \\
\hline
\end{tabular}

CTRP1 — protein-1 related with C1q/TNF

Table 6. Correlations of blood adipocytokines concentrations with NIHSS, Barthel scale in patients with cerebral stroke

\begin{tabular}{llccc}
\hline & & NIHSS scale & Barthel start & Barthel end \\
\hline \multirow{2}{*}{ Omentin-1 [ng/mL] } & $\mathrm{R}$ & 0.2384 & -0.1915 & -0.2926 \\
\cline { 2 - 5 } & $\mathrm{P}$ value & 0.1678 & 0.2703 & 0.0881 \\
\hline \multirow{2}{*}{ Irisin [ng/mL] } & $\mathrm{R}$ & 0.0200 & 0.0154 & -0.0446 \\
\cline { 2 - 5 } & $\mathrm{P}$ value & 0.8952 & 0.9195 & 0.7685 \\
\hline \multirow{2}{*}{ Vaspin [ng/mL] } & $\mathrm{R}$ & -0.1883 & 0.1608 & 0.1077 \\
\cline { 2 - 5 } & $\mathrm{P}$ value & 0.2101 & 0.4761 \\
\hline \multirow{2}{*}{ Nesfatin-1 [ng/mL] } & $\mathrm{R}$ & -0.0737 & 0.0507 & 0.0702 \\
\cline { 2 - 5 } & $\mathrm{P}$ value & 0.6304 & 0.7409 & -0.2459 \\
\hline \multirow{2}{*}{ CTRP1 [ng/mL] } & $\mathrm{R}$ & 0.3569 & -0.3099 & 0.0995 \\
\cline { 2 - 5 } & $\mathrm{P}$ value & $\mathbf{0 . 0 1 4 9}$ & 0.0571 & \\
\hline
\end{tabular}

CTRP1 — protein-1 related with C1q/TNF; NIHHS scale — scale of National Institutes of Health Stroke Scale; Barthel start — Barthel scale evaluation on admission; Barthel end - Barthel scale evaluation on ninth day after admission 
Table 7. Correlations of blood adipocytokines concentrations with intima-media (IM) complex

\begin{tabular}{lcc}
\hline & \multicolumn{2}{c}{ Intima-media complex } \\
\hline & $\mathbf{R}$ & $\mathbf{p}$ value \\
\hline Omentin-1 $[\mathrm{ng} / \mathrm{mL}]$ & -0.1068 & 0.5743 \\
\hline Irisin $[\mathrm{ng} / \mathrm{mL}]$ & 0.2635 & 0.0959 \\
\hline Vaspin $[\mathrm{ng} / \mathrm{mL}]$ & -0.1074 & 0.2101 \\
\hline Nesfatin-1 $[\mathrm{ng} / \mathrm{mL}]$ & 0.1311 & 0.4201 \\
\hline CTRP1 $[\mathrm{ng} / \mathrm{mL}]$ & -0.0358 & 0.8243 \\
\hline
\end{tabular}

CTRP1 — protein-1 related with C1q/TNF

\section{Discussion}

The literature shows numerous publications that attribute the role of developing IS to adiponectin, resistin, or leptin $[15,16]$. There are only limited reports describing the pathogenic role in developing stroke of other, less renowned adipocytokines, including omentin-1, CTRP1, nesfatin-1, irisin, and vaspin. Proving the correlation between the existence of cerebrovascular events and the concentration of adipose-derived hormones in the blood of IS patients can extend the knowledge of the pathogenesis of IS.

\section{Omentin-1}

The literature contains analyses of the omentin-1 level in the context of atherosclerosis. Shang et al. [17] proved that the serum concentration of omentin-1 can be a sensitive biomarker for the development and progression of atherosclerotic lesions in the coronary vessels of persons with metabolic syndrome. Other study results show their correlation with the level of atherosclerotic lesions. A negative correlation between the blood serum concentration of omentin-1 and the clinical exponents for atherosclerosis severity in patients with type 2 diabetes and a metabolic syndrome was found [18]. Multiple regression analysis conducted by Yool H. et al. [19] showed that the concentration of omentin-1 was an independent determining factor for atherosclerosis severity in patients with type 2 diabetes.
It was also found that the serum concentration of omentin-1 was lower in persons with acute coronary syndrome and with stable angina pectoris than in persons without those disorders. In addition, the persons with acute coronary syndrome showed lower omentin-1 concentration than patients with stable angina pectoris [20].

In recent years there have been reports concerning the role of omentin-1 in IS. Wu et al. [21] attempted to assess the impact of serum omentin-1 concentration on the prognosis of IS patients, without diabetes in their medical history. It was found that a low omentin-1 concentration increased the risk of treatment failure. On the other hand, Xu et al. [22] in their study found that omentin-1 could be a biomarker used to predict the instability of an atherosclerotic plaque in patients with IS. Patients with IS and an unstable atherosclerotic plaque had a considerably higher level of the adipocytokine than patients with a stable atherosclerotic plaque. In our study, to our surprise, we found a higher omentin-1 concentration in the group of stroke patients. We found no correlation between the omentin-1 level and the stroke severity, IMT, or the occurrence of stenosis in carotid vessels.

\section{Irisin}

Irisin has been analysed several times in the context of physical effort. It is suggested that its secretion increases with an intensification of physical effort, especially after high-intensity resistance training [23]. The results of studies performed to date are divergent [24]. For example, Norheim et al. [25] reported a 2-fold increase in the irisin level directly after high-intensity physical effort, but its concentration reduced in response to a 12-week mixed strength-endurance training.

Irisin has become the focus of attention as a potential new marker not only for obesity, but also for obesity-related metabolic disorders [26]. A negative correlation between serum irisin levels and the incidence rate of coronary disease was described [27]. A lower irisin level was not only an independent predictive factor for complications in major vessels in type 2 diabetes [26],

Table 8. Omentin-1, irisin, vaspin, irisin, nesfatin-1, and CTRP1 levels in patients with ischaemic stroke with and without carotid artery stenosis detected in carotid Doppler ultrasonography

\begin{tabular}{lccc}
\hline & Patients without stenosis $(\mathbf{n}=\mathbf{3 6})$ & Patients with stenosis $(\mathbf{n}=\mathbf{5})$ & p value \\
\hline Omentin-1 [ng/mL] & $513(\mathrm{SD} \pm 216.24)$ & $387.93 \mathrm{SD} \pm 39.38)$ & 0.3498 \\
\hline Irisin $[\mathrm{ng} / \mathrm{mL}]$ & $4.71(\mathrm{SD} \pm 1.36)$ & $5.55(\mathrm{SD} \pm 1.79)$ & 0.2827 \\
\hline Vaspin $[\mathrm{ng} / \mathrm{mL}]$ & $0.206(\mathrm{SD} \pm 0.152)$ & $0.303(\mathrm{SD} \pm 0.214)$ & 0.3397 \\
\hline Nesfatin-1 $[\mathrm{ng} / \mathrm{mL}]$ & $271.3(\mathrm{SD} \pm 165.4)$ & $436.5(\mathrm{SD} \pm 76.5)$ & $\mathbf{0 . 0 2 1 3}$ \\
\hline CTRP1 $[\mathrm{ng} / \mathrm{mL}]$ & $467.2(\mathrm{SD} \pm 176.1)$ & $347.5(\mathrm{SD} \pm 130.9)$ & 0.0994 \\
\hline
\end{tabular}

CTRP1 — protein-1 related with C1q/TNF 
but also for cardiovascular events, including MI in the population of non-diabetic patients [29].

In the literature there are only a small number of reports from the last 4 years on the role of irisin in IS. Li et al. [30] found that the concentration of serum irisin in mice fell after IS. Moreover, the irisin level was negatively correlated with the cerebral infarction volume, advanced neurological deficit, and with the concentration of TNF- $\alpha$ and IL- 6 . Administering recombined irisin to mice with IS reduced the volume of cerebral infarction and neurological deficits. Another experimental study on mice, inducing their global cerebral ischaemia, confirmed that irisin improved neurologic functions, and additionally it was found to reduce apoptosis and alleviate damage to neurons [31]. A study covering a Chinese population including more than 1500 persons with IS, subjected to a 6-month neurological observation, showed that irisin level reduction is associated with worse prognosis [32]. However, our analysis did not show any correlation between irisin level and the severity of stroke, but we confirmed that the patients with IS showed higher concentrations of irisin than healthy persons.

\section{Vaspin}

In obese patients with a normal glucose tolerance, the level of vaspin was usually elevated. Its secretion increases with the volume of adipose tissue and BMI [33]. In addition, it was shown that the serum concentration of vaspin was higher in females than in males with normal glucose tolerance, but we did not note such differences [34]. It is suggested that the increase in vaspin expression can be a compensation mechanism as a response to the increase in obesity and insulin resistance [35]. The concentration of vaspin can also reflect the level of glycaemic control. In patients with type 2 diabetes a positive correlation between the serum concentration of vaspin and the $\mathrm{HbA}_{1 \mathrm{c}}$ value was observed [36]. Some authors suggest that vaspin protects vascular endothelial cells against apoptosis induced by free fatty acids, which indicates that it can show an antiatherosclerotic effect [11]. Li et al. [37] showed that a low vaspin concentration correlated with the severity of ischaemic heart disease and unstable angina pectoris.

Only a few studies assessing the concentration of vaspin after IS have been performed so far, and the published results are very divergent. Aust et al. [38] found lower vaspin concentrations in patients with carotid artery stenosis and cerebral ischaemic event in their history. At the same time, the study did not show any correlation between vaspin serum concentration and the severity of atherosclerotic lesions. However, they found a positive correlation between the serum concentration of vaspin and leptin, another adipocyto- kine related to the development of atherosclerosis. Another study showed a lower vaspin level in patients with acute IS [39]. However, we did not confirm such a correlation. The group of patients with and without stroke was homogeneous in terms of the adipocytokine concentration. Some authors, conversely, noted higher levels of the adipocytokine in patients with IS [40]. It should be emphasised that despite the fact that the above-mentioned studies (including ours) refer to acute-phase IS, they cover only small groups of patients, and we do not possess any meta-analytic data.

\section{Nesfatin-1}

As already mentioned above, nesfatin-1 is a peptide with an anorexigenic and gastroprotective effect $[13,14]$. In addition, it has been found that nesfatin- 1 affects the cardiovascular system. By stimulating the action of the sympathetic nervous system, it increases the average arterial blood pressure [41]. Lower levels of nesfatin-1 were observed in patients with acute MI [42] and in patients with impaired flow through coronary vessels [43]. Ding et al. [44] found a correlation between lowered nesfatin-1 serum levels and the development and intensification of peripheral vessel diseases in diabetic patients. The above-mentioned nesfatin- 1 related studies may suggest that it plays a role in atherosclerosis, and consequently in the mechanism of developing IS. Kuyumcu [45] investigated the correlation between nesfatin- 1 level and the atherosclerosis of carotid arteries and found that the serum levels of nesfatin- 1 in patients with carotid artery stenosis were lower, especially if the stenosis exceeded $60 \%$. In addition, the concentration of the adipocytokine was negatively correlated with the speed of carotid artery narrowing. The low level of nesfatin-1 proved to be an independent risk factor for carotid artery stenosis. Observations showed that its lower concentrations were concomitant with an unstable atherosclerotic plaque.

Our study showed lower nesfatin-1 concentrations in patients with IS with no correlation with stroke severity. Interestingly, patients with stenosis had higher nesfatin-1 concentrations than patients without it. However, it should be noted that the group consisted only of five patients. A study performed by Erfani S et al. [46] for the first time showed that administering nesfatin-1 to rats with induced cerebral ischaemia prevents the death of neurons.

\section{CTRP1}

CTRP1 acts as a blood pressure regulator [47]. Patients with arterial hypertension have higher CTRP1 levels as compared to normotensive persons. Tang et al. [48] showed that an increase in CTRP1 and IL-6 levels could be a strong predictive factor for ischaemic heart 
disease. Also, Lu et al. [49] documented that CTRP1 was elevated in patients with stable coronary disease, and by using a multidimensional analysis they concluded that CTRP1 was an independent risk factor for its occurrence. CTRP1 levels grow with the increase of CAD severity. In addition, they are positively correlated with the increase of TNF and IL-6 levels. Also, the correlation of CTRP1 with a future cardiovascular risk was investigated. In patients undergoing coronary angiography they measured the level of CTRP1 and then observed them for 8 years for future cardiovascular events (including deaths caused by cardiovascular incidents, the occurrence of myocardial infarction, and stroke). Obesity, metabolic syndrome, type 2 diabetes, and fatty liver disease (FLD) were associated with a higher CTRP1 level. High CTRP1 serum levels were significantly related to the risk of future cardiovascular events (including stroke) [50].

Despite such a large number of unambiguous reports on elevated CTRP1 levels in coronary artery disease, we do not possess any studies concerning the level of that adipocytokine in IS. Our analysis showed not only significantly higher CTRP1 concentrations in patients with IS, but also defined CTRP1 to be an independent predictive factor for IS. Moreover, higher CTRP1 concentrations were associated with more severe course of stroke.

Summing up, the lower levels of nesfatin-1 and irisin in the blood of patients with IS observed in our study are convergent with the studies conducted by other authors, which allows us to assume that there might be pathogenetic connection between these levels and IS.

The results of our study show that CTRP1 can be a useful diagnostic marker for IS, as is the case for ischaemic heart disease.

\section{Conclusions}

An early detection of risk factors for vascular diseases and implementing primary prevention leads not only to the reduction in morbidity and mortality caused by stroke, but also improves patients' quality of life and reduces the costs of treating the consequences of those diseases. The role of adipocytokines in the pathogenesis of IS, repeatedly emphasised in the literature, and confirmed by us, urges us to investigate more and more new adipose-derived hormones. Clinicians hope to find sensitive markers for vascular diseases, including cerebrovascular diseases, which could be used to identify patients endangered by the diseases.

Although, our analysis has shown that CTRP1 turned out to be an independent risk factor for stroke, it is almost impossible for us to compare our study results to the results obtained in studies performed by other authors. It seems that there is an urgent need to continue this new line of studies on the pathogenesis of IS.

\section{Funding}

Information on grants and other funding sources: KNW $1-080 / \mathrm{N}-8-0$.

\section{References}

1. Łabuz-Roszak B, Starostka-Tatar A, Lasek-Bal A, et al. Diagnostics, treatment and secondary prevention of ischemic stroke in the Silesian Province, Poland between 2009 and 2015. Neurol Neurochir Pol. 2018; 52(2): 235-242, doi: 10.1016/j.pjnns.2017.11.003, indexed in Pubmed: 29198761.

2. Chwalba A, Machura E, Ziora K, et al. The role of adipokines in the pathogenesis and course of selected respiratory diseases. Endokrynol Pol. 2019; 70(6): 504-510, doi: 10.5603/EP.a2019.0051, indexed in Pubmed: 31891413.

3. Kershaw EE, Flier JS. Adipose tissue as an endocrine organ. J Clin Endocrinol Metab. 2004; 89(6): 2548-2556, doi: 10.1210/jc.2004-0395, indexed in Pubmed: 15181022.

4. Baranowska-Bik A, Kalisz M, Martyńska L, et al. Plasma adiponectin array in women with Alzheimer's disease. Endokrynol Pol. 2018; 69(5): 550-559, doi: 10.5603/EP.a2018.0055, indexed in Pubmed: 30117532.

5. Prugger C, Luc G, Haas B, et al. PRIME Study Group. Adipocytokines and the risk of ischemic stroke: the PRIME Study. Ann Neurol. 2012; 71(4): 478-486, doi: 10.1002/ana.22669, indexed in Pubmed: 22522440.

6. Głogowska-Szeląg J, Kos-Kudła B, Marek B, et al. Assessment of selected adipocytokines in obese women with postmenopausal osteoporosis. Endokrynol Pol. 2019; 70(6): 478-483, doi: 10.5603/EP.a2019.0043, indexed in Pubmed: 31566247.

7. Olszanecka-Glinianowicz M, Kocełak P, Orlik B, et al. Nowe adipokiny - korzystne czy niekorzystne $\mathrm{w}$ aspekcie patogenezy insulinooporności? Endokr Otył Zab Przem Mat. 2009; 5(4): 236-242.

8. de Souza Batista CM, Yang RZ, Lee MJ, et al. Omentin plasma levels and gene expression are decreased in obesity. Diabetes. 2007; 56(6): 1655-1661, doi: 10.2337/db06-1506, indexed in Pubmed: 17329619.

9. Pukajło K, Kolackov K, Łaczmański $€$, et al. [Irisin — a new mediator of energy homeostasis]. Postepy Hig Med Dosw (Online). 2015; 69: 233-242, doi: 10.5604/17322693.1141097, indexed in Pubmed: 25720610.

10. Jeong E, Youn BS, Kim DW, et al. Circadian rhythm of serum vaspin in healthy male volunteers: relation to meals. J Clin Endocrinol Metab. 2010; 95(4): 1869-1875, doi: 10.1210/jc.2009-1088, indexed in Pubmed: 20156923.

11. Blüher M. Vaspin in obesity and diabetes: pathophysiological and clinical significance. Endocrine. 2012; 41(2): 176-182, doi: 10.1007/s12020-011-9572-0, indexed in Pubmed: 22139797.

12. Shimizu H, Oh-I S, Hashimoto K, et al. Peripheral administration of nesfatin-1 reduces food intake in mice: the leptin-independent mechanism. Endocrinology. 2009; 150(2): 662-671, doi: 10.1210/en.2008-0598, indexed in Pubmed: 19176321.

13. Szlachcic A, Surmiak M, Majka J, et al. Nesfatin-1: a new hormone in the control of food intake and the mechanism of damage and protection of gastric mucosa. Gastroenterol Rev. 2012; 6: 339-350, doi: 10.5114/pg.2012.33041.

14. Schäffler A, Buechler C. CTRP family: linking immunity to metabolism. Trends Endocrinol Metab. 2012; 23(4): 194-204, doi: 10.1016/j. tem.2011.12.003, indexed in Pubmed: 22261190.

15. Kazimierczak-Kabzińska A, Kajdaniuk D, Siemińska L, et al. Selected adipose tissue hormones in the blood of patients with ischaemic cerebral stroke. Endokrynol Pol. 2020; 71(1): 21-26, doi: 10.5603/EP.a2019.0057, indexed in Pubmed: 31851370.

16. Bienek R, Marek B, Kajdaniuk D, et al. Adiponectin, leptin, resistin and insulin blood concentrations in patients with ischaemic cerebral stroke. Endokrynol Pol. 2012; 63(5): 338-345, indexed in Pubmed: 23115066.

17. Shang FJ, Wang JP, Liu XT, et al. Serum omentin-1 levels are inversely associated with the presence and severity of coronary artery disease in patients with metabolic syndrome. Biomarkers. 2011; 16(8): 657-662, do i: 10.3109/1354750X.2011.622789, indexed in Pubmed: 21988056.

18. Shibata R, Ouchi N, Takahashi R, et al. Omentin as a novel biomarker of metabolic risk factors. Diabetol Metab Syndr. 2012; 4(1): 37, doi: 10.1186/1758-5996-4-37, indexed in Pubmed: 22835063.

19. Yoo HJ, Hwang SY, Hong HoC, et al. Association of circulating omentin-1 level with arterial stiffness and carotid plaque in type 2 diabetes. Cardiovasc Diabetol. 2011; 10: 103, doi: 10.1186/1475-2840-10-103, indexed in Pubmed: 22108456.

20. Zhong X, Zhang Hy, Tan H, et al. Association of serum omentin-1 levels with coronary artery disease. Acta Pharmacol Sin. 2011; 32(7): 873-878, doi: 10.1038/aps.2011.26, indexed in Pubmed: 21602837. 
21. Wu DM, Wang S, Wen X, et al. Impact of serum omentin-1 levels on functional prognosis in nondiabetic patients with ischemic stroke. Am J Transl Res. 2019; 11(3): 1854-1863, indexed in Pubmed: 30972209.

22. Xu T, Zuo P, Cao L, et al. Omentin-1 is Associated with Carotid Plaque Instability among Ischemic Stroke Patients. J Atheroscler Thromb. 2018 25(6): 505-511, doi: 10.5551/jat.42135, indexed in Pubmed: 29225325

23. Huh JY, Siopi A, Mougios V, et al. Irisin in response to exercise in humans with and without metabolic syndrome. J Clin Endocrinol Metab. 2015; 100(3): E453-E457, doi: 10.1210/jc.2014-2416, indexed in Pubmed: 25514098.

24. Moraes C, Leal VO, Marinho SM, et al. Resistance exercise training does not affect plasma irisin levels of hemodialysis patients. Horm Metab Res. 2013; 45(12): 900-904, doi: 10.1055/s-0033-1354402, indexed in Pubmed: 24013946.

25. Norheim F, Langleite TM, Hjorth M, et al. The effects of acute and chronic exercise on PGC- $1 \alpha$, irisin and browning of subcutaneous adipose tissue in humans. FEBS J. 2014; 281(3): 739-749, doi: 10.1111/febs.12619, indexed in Pubmed: 24237962

26. Chen Jq, Huang Yy, Gusdon AM, et al. Irisin: a new molecular marker and target in metabolic disorder. Lipids Health Dis. 2015; 14: 2 doi: 10.1186/1476-511X-14-2, indexed in Pubmed: 25588692

27. Anastasilakis AD, Koulaxis D, Kefala N, et al. Circulating irisin levels are lower in patients with either stable coronary artery disease (CAD) or myocardial infarction (MI) versus healthy controls, whereas follistatin and activin $\mathrm{A}$ levels are higher and can discriminate $\mathrm{MI}$ from $\mathrm{CAD}$ with similar to CK-MB accuracy. Metabolism. 2017; 73: 1-8, doi: 10.1016/j. metabol.2017.05.002, indexed in Pubmed: 28732565.

28. Zhang M, Chen P, Chen S, et al. The association of new inflammatory markers with type 2 diabetes mellitus and macrovascular complications: a preliminary study. Eur Rev Med Pharmacol Sci. 2014; 18(11): 1567-1572, indexed in Pubmed: 24943964.

29. Emanuele E, Minoretti P, Pareja-Galeano H, et al. Serum irisin levels, precocious myocardial infarction, and healthy exceptional longevity. Am J Med. 2014; 127(9): 888-890, doi: 10.1016/j.amjmed.2014.04.025, indexed in Pubmed: 24813865.

30. Li DJ, Li YH, Yuan HB, et al. The novel exercise-induced hormone irisin protects against neuronal injury via activation of the Akt and ERK1/2 signaling pathways and contributes to the neuroprotection of physical exercise in cerebral ischemia. Metabolism. 2017; 68: 31-42, doi: 10.1016/j. metabol.2016.12.003, indexed in Pubmed: 28183451.

31. Jin Z, Guo P, Li X, et al. Neuroprotective effects of irisin against cerebra ischemia/ reperfusion injury via Notch signaling pathway. Biomed Pharmacother. 2019; 120: 109452, doi: 10.1016/j.biopha.2019.109452, indexed in Pubmed: 31561067.

32. Tu WJ, Oiu HC, Cao JL, et al. Decreased Concentration of Irisin Is Associated with Poor Functional Outcome in Ischemic Stroke. Neurotherapeutics. 2018; 15(4): 1158-1167, doi: 10.1007/s13311-018-0651-2, indexed in Pubmed: 30030698.

33. Li Q, Chen R, Moriya J, et al. A novel adipocytokine, visceral adipose tissue-derived serine protease inhibitor (vaspin), and obesity. J Int Med Res. 2008; 36(4): 625-629, doi: 10.1177/147323000803600402, indexed in Pubmed: 18652756.

34. Youn BS, Klöting N, Kratzsch J, et al. Serum vaspin concentrations in human obesity and type 2 diabetes. Diabetes. 2008; 57(2): 372-377, doi: 10.2337/db07-1045, indexed in Pubmed: 17991760.

35. Klöting N, Kovacs $\mathrm{P}$, Kern M, et al. Central vaspin administration acutely reduces food intake and has sustained blood glucose-lowering ef- fects. Diabetologia. 2011; 54(7): 1819-1823, doi: 10.1007/s00125-011-2137-1, indexed in Pubmed: 21465327

36. Gulcelik NE, Karakaya J, Gedik A, et al. Serum vaspin levels in type 2 diabetic women in relation to microvascular complications. Eur J Endocrinol. 2009; 160(1): 65-70, doi: 10.1530/EJE-08-0723, indexed in Pubmed: 18952766.

37. Li HL, Peng WH, Cui ST, et al. Vaspin plasma concentrations and mRNA expressions in patients with stable and unstable angina pectoris. Clin Chem Lab Med. 2011; 49(9): 1547-1554, doi: 10.1515/CCLM.2011.236, indexed in Pubmed: 21913793.

38. Aust G, Richter O, Rohm S, et al. Vaspin serum concentrations in patients with carotid stenosis. Atherosclerosis. 2009; 204(1): 262-266, doi: 10.1016/j.atherosclerosis.2008.08.028, indexed in Pubmed: 18848328

39. Kadoglou NPE, Fotiadis G, Lambadiari V et al Serum levels of novel adipokines in patients with acute ischemic stroke: potential contribution to diagnosis and prognosis. Peptides. 2014; 57: 12-16, doi: 10.1016/j. peptides.2014.04.008, indexed in Pubmed: 24768795.

40. Cura HS, Özdemir HH, Demir CF, et al. Investigation of vaspin level in patients with acute ischemic stroke. J Stroke Cerebrovasc Dis. 2014; 23(3): 453-456, doi: 10.1016/j.jstrokecerebrovasdis.2013.03.023, indexed in Pubmed: 23594688

41. Yosten GLC, Samson WK. Nesfatin-1 exerts cardiovascular actions in brain: possible interaction with the central melanocortin system. Am J Physiol Regul Integr Comp Physiol. 2009; 297(2): R330-R336, doi: 10.1152/ajpregu.90867.2008, indexed in Pubmed: 19474390.

42. Dai H, Li X, He T, et al. Decreased plasma nesfatin-1 levels in patients with acute myocardial infarction. Peptides. 2008; 46: 167-171, doi: 10.1152/ajpregu.90867.2008, indexed in Pubmed: 23806888.

43. Kuyumcu MS, Kuyumcu A, Yayla Ç, et al. Nesfatin-1 levels in patients with slow coronary flow. Kardiol Pol. 2018; 76(2): 401-405, doi: 10.5603/KP.a2017.0210, indexed in Pubmed: 29131290.

44. Ding S, Qu W, Dang S, et al. Serum nesfatin-1 is reduced in type 2 diabetes mellitus patients with peripheral arterial disease. Med Sci Monit. 2015; 21: 987-991, doi: 10.12659/MSM.892611, indexed in Pubmed: 25841171.

45. Kuyumcu A. The relationship between nesfatin-1 and carotid artery stenosis. Scand Cardiovasc J. 2018; 52(6): 328-334, doi: 10.1080/1401743 1.2018.1547840, indexed in Pubmed: 30599786.

46. Erfani S, Moghimi A, Aboutaleb N, et al. Protective effects of Nesfatin-1 peptide on cerebral ischemia reperfusion injury via inhibition of neuronal cell death and enhancement of antioxidant defenses. Metab Brain Dis. 2019; 34(1): 79-85, doi: 10.1007/s11011-018-0323-2, indexed in Pubmed: 30269302.

47. Jeon JHo, Kim Ky, Kim JH, et al. A novel adipokine CTRP1 stimulates aldosterone production. FASEB J. 2008; 22(5): 1502-1511, doi: 10.1096/fj.07-9412com, indexed in Pubmed: 18171693

48. Tang JN, Shen DL, Liu CL, et al. Plasma levels of C1q/TNF-related protein 1 and interleukin 6 in patients with acute coronary syndrome or stable angina pectoris. Am J Med Sci. 2015; 349(2): 130-136, doi: 10.1097/MAJ.0000000000000378, indexed in Pubmed: 25635749.

49. Lu L, Zhang RY, Wang XQ, et al. C1q/TNF-related protein-1: an adipokine marking and promoting atherosclerosis. Eur Heart J. 2016; 37(22): 1762-1771, doi: 10.1093/eurheartj/ehv649, indexed in Pubmed: 26705391.

50. Muendlein A, Leiherer A, Saely C, et al. The novel adipokine CTRP1 is significantly associated with the incidence of major adverse cardiovascular events. Atherosclerosis. 2019; 286: 1-6, doi: 10.1016/j.atherosclerosis.2019.04.222, indexed in Pubmed: 31051410 